\title{
БОЛЕЗНЬ ФРИДРЕЙХА: ЭКСПРЕССИЯ ГЕНА ГХN И ЕЕ ВЗАИМОСВЯЗЬ С ОСОБЕННОСТЯМИ МЕТИЛИРОВАНИЯ ДНК
}

Е. Ю. Федотова $凶$, Н. Ю. Абрамычева, Е. П. Нужный, М. В. Ершова, С. А. Клюшников, С. Н. Иллариошкин

Научный центр неврологии, Москва, Россия

Болезнь Фридрейха (БФ) - наиболее частая аутосомно-рецессивная атаксия, связанная с экспансией тандемных некодирующих GАА-повторов в гене FXN. Нарушение транскрипции и недостаточность белка фратаксина являются ключевыми звеньями патогенеза заболевания. Целью работы было исследовать экспрессию MPHК гена FXN и провести анализ клинических, генетических и эпигенетических корреляций в группе пациентов с гомозиготной экспансией повторов, в группе их родственников с гетерозиготной экспансией и в контрольной группе. Уровень мРНК гена FХN определяли с помощью полимеразной цепной реакции в реальном времени. Паттерн метилирования СрG-сайтов оценивали методом прямого секвенирования после бисульфитной обработки. В результате работы получены разграничительные значения между группой пациентов БФ, группой гетерозиготных носителей и контрольной группой (15 и 79\% соответственно). При проведении клинико-генетических сопоставлений с уровнем экспрессии FХN значимых корреляций выявлено не было. При сопоставлении экспрессии гена с эпигенетическим профилем было установлено, что экспрессия подавляется при гиперметилировании ряда CpG-сайтов выше области тринуклеотидных повторов и некоторых не-СрG-сайтов ниже области повторов. Таким образом, выявленные сайты могут быть рассмотрены в качестве точки приложения таргетного эпигенетического редактирования для увеличения транскрипции FXN и, следовательно, для таргетной терапии заболевания.

Ключевые слова: болезнь Фридрейха, экспрессия гена, эпигенетика, метилирование ДНК, не-СрG-метилирование, ДНК-диагностика, таргетная терапия Финансирование: работа выполнена при поддержке гранта РНФ (номер проекта 17-75-20211).

Информация о вкладе авторов: все авторы внесли равнозначный вклад в проведение исследования и подготовку статьи, прочли и одобрили ее финальную версию перед публикацией.

Соблюдение этических стандартов: исследование одобрено этическим комитетом ФГБНУ НЦН (протокол № 11-3/17 от 18 октября 2017 г.). Все пациенты подписали информированное согласие на участие в исследовании.

$\triangle$ Для корреспонденции: Екатерина Юрьевна Федотова

Волоколамское ш., д. 80, г. Москва; ekfedotova@gmail.com

Статья получена: 22.08.2019 Статья принята к печати: 13.09.2019 Опубликована онлайн: 25.09.2019

DOI: $10.24075 /$ vrgmu.2019.062

\section{FRIEDREICH ATAXIA: FXN GENE EXPRESSION AND ITS RELATIONSHIP WITH DNA METHYLATION PATTERN}

\author{
Fedotova EYu凶, Abramycheva NYu, Nuzhny EP, Ershova MV, Klyushnikov SA, Illarioshkin SN
}

Research Center of Neurology, Moscow, Russia

\begin{abstract}
Friedreich ataxia (FRDA) is the most common autosomal recessive ataxia associated with the non-coding GAA tandem repeats expansion in the FXN gene. Transcription impairment and frataxin protein deficiency are the key features of the disease pathogenesis. Our research was aimed to study the FXN gene mRNA expression as well as to carry out the clinical, genetic and epigenetic correlation analysis in a group of patients with homozygous expansion, in a group of their relatives with heterozygous expansion and in a control group. The FXN mRNA level was determined using the real-time polymerase chain reaction. Methylation pattern of $\mathrm{CpG}$ sites was evaluated by direct bisulfite sequencing. As a result of the study, the threshold values were obtained between the FRDA patients group, the group of heterozygous carriers and the control group (15 and 79\%, respectively). The clinical and genetic features comparison with the FXN expression level revealed no significant correlation. When comparing gene expression with an epigenetic profile, it was found that hypermethylation of a number of $\mathrm{CpG}$ sites upstream of the trinucleotide repeats and some non-CpG sites downstream of the region of repeats inhibited expression. Thus, the identified methylated sites may be considered as a target for epigenome editing to increase the FXN transcription and, consequently, for target therapy of the disease.
\end{abstract}

Keywords: Friedreich ataxia, gene expression, epigenetics, DNA methylation, non-CpG methylation, DNA diagnostics, target therapy

Funding: the study is supported by grant of the Russian Science Foundation (project № 17-75-20211).

Author contribution: all authors contributed to the study and preparation of the article equally, read and approved the final version before publishing.

Compliance with ethical standards: the study was approved by the Ethics Committee of Research Center of Neurology (protocol № 11-3/17 dated October 18, 2017). Informed consent was obtained from all study participants.

$\triangle$ Correspondence should be addressed: Ekaterina Yu. Fedotova Volokolamskoe shosse, 80, Moscow, 125367; ekfedotova@gmail.com

Received: 22.08.2019 Accepted: 13.09.2019 Published online: 25.09.2019

DOI: $10.24075 /$ brsmu.2019.062

Болезнь Фридрейха (БФ) - наиболее частая аутосомнорецессивная атаксия, связанная с экспансией тандемных тринуклеотидных GAA-повторов в 1-м интроне гена FXN $[1,2]$. Молекулярной основой заболевания является недостаточность продукта гена - митохондриального белка фратаксина [3]. Считается, что значительная экспансия в сотни нуклеотидов, имеющая место при БФ, препятствует транскрипции соответствующей мРНК FXN [2].
В ряде исследований показано, что в критическом локусе ДНК, содержащем ген FXN, в случае экспансии образуется гетерохроматин (неактивный хроматин) с подавлением процессов транскрипции [4]. Ему соответствуют определенные модификации гистонов - уменьшение ацетилирования и повышение триметилирования, что показано у пациентов с БФ [5-7]. Наряду с модификацией гистонов наблюдают и другие эпигенетические феномены усиление ДНК-метилирования в промоторе и в области 1-го 
интрона, расположенной выше участка GAA-экспансии (UP-GAA), и снижение ДНК-метилирования в области 1-го интрона ниже GAA-экспансии (DOWN-GAA). Известно, что метилирование цитозина в динуклеотидной паре цитозингуанин (CpG) в промоторе приводит к уменьшению экспрессии гена, т. е. метилирование ДНК в UP-GAAобласти предположительно ингибирует транскрипцию FXN и приводит к снижению уровня фрратаксина [8].

ДНК-метилирование и модификации гистонов - это взаимосвязанные эпигенетические процессы. В частности, уровень ДНК-метилирования может быть прогностически важным маркером для ингибиторов гистоновых деацетилаз, клинические испытания которых проводят с целью эпигенетической терапии БФ. При этом есть мнение, что при БФ ДНК-метилирование первично по отношению К модификации гистонов [9].

В последние годы стали появляться работы, исследующие значение так называемого не-CpGметилирования (non-CpG methylation). При этом типе происходит метилирование цитозина в паре с другими, отличными от гуанина, нуклеотидами - аденином, тимином, цитозином. Наибольший уровень не-CpG-метилирования был найден в стволовых клетках и клетках нервной системы $[10,11]$, что позволяет предполагать особую роль данного варианта эпигенетической модификации в реализации функций нервной системы в норме и при патологии. До настоящего времени не-СpG-метилирование при БФ не исследовали.

Целью работы было исследовать уровень экспрессии MPHK гена FXN и провести анализ клинических, гентических и эпигенетических корреляций у пациентов с БФ и гетерозиготных носителей мутации FXN.

\section{ПАЦИЕНТЫ И МЕТОДЫ}

Исследование проводили на базе 5-го неврологического отделения Научного центра неврологии с 2017 по 2019 г Была изучена группа пациентов с БФ и подтвержденной гомозиготной экспансией GAA-повторов в гене FXN $(n=8$; 3 женщины и 5 мужчин). Средний возраст больных составил 29,9 \pm 9,5 лет, возраст дебюта заболевания $13,8 \pm$ 6,7 лет, длительность заболевания - 16,0 \pm 9,3 лет. Критерии включения пациентов в группу с БФ: наличие клинического диагноза заболевания с положительными результатами молекулярно-генетической диагностики (гомозиготная экспансия тандемных GAA-повторов в 1-м интроне гена FXN). Среднее число GAA-повторов в коротком аллеле гена в группе составило 506,0 \pm 232,0 (GAA1), в длинном - 718,8 $\pm 143,8$ (GAA2). Пациентов клинически обследовали по шкале оценки атаксии SARA (средний балл в группе - 23,1 $\pm 11,4)$ и по шкале Монреальской когнитивной оценки МоСА (средний балл 24,6 $\pm 2,7)$; определяли также наличие кардиомиопатии (5/8), нарушений углеводного обмена (3/8), сколиоза и деформации стоп (6/8). Критерии исключения: отсутствие верифицированного диагноза заболевания.

Основную группу пациентов сравнивали с группой гетерозиготных носителей мутации в гене FXN, обозначаемой далее как GAA-гетерозиготы $(n=6 ; 5$ женщин и 1 мужчина); в эту группу вошли родственники больных БФ первой степени родства. Группа сравнения была старше по возрасту (53,7 \pm 19,6 лет) по сравнению с больными БФ (за счет родителей пациентов). Для гетерозиготных носителей критерием включения было наличие гетерозиготной GAAэкспансии. Длина экспандированного аллеля FXN в группе составила 664,0 \pm 283,7 повторов (GAA2). Контрольная группа $(n=10)$ без экспансии GAA-повторов в гене FXN была сопоставима по полу и возрасту с основной группой.

Образцы геномной ДНК выделяли из лейкоцитов периферической крови с помощью набора Wizard Genomic DNA Purification Kit (Promega; США). Наличие экспансии GAA-повторов в гене FXN оценивали методом полимеразной цепной реакции (ПЦР) соответствующей области с последующим разделением ампликонов в агарозном геле.

Паттерн метилирования определяли методом прямого секвенирования соответствующих участков ДНК после бисульфитной обработки с помощью набора EZ DNA Methylation Kit (Zymo Research; США) согласно методике производителя. У каждого обследуемого определяли уровень метилирования CpG-сайтов в трех основных значимых областях гена FXN: в промоторной области, UP-GAA-области и DOWN-GAA-области. В промоторной области FXN были исследованы 16 CpG-сайтов, в UPGAA-области - 67 CpG-сайтов, в DOWN-GAA-области 21 CpG-сайт (с нумерацией от 5'-конца соответствующей области). Степень метилирования сайта рассчитывали по отношению высоты синего пика (метилированный цитозин, С) к суммарной высоте синего и красного пиков (метилированный и неметилированный цитозин, C + T).

Кроме исследования CpG-сайтов в работе проводили поиск и анализ метилирования не-CpG-сайтов. Не-CpGсайты выявляли при анализе сиквенса по метилированному цитозину (mC), предшествующему аденину, тимину или цитозину (соответственно, $\mathrm{mCA}, \mathrm{mCT}, \mathrm{mCC}$ ).

Оценку уровня экспрессии гена FXN проводили путем измерения количества мРНК гена FXN методом ПЦР в реальном времени (ПЦР-РВ) в исследуемых образцах по следующей схеме. Забор периферической крови осуществляли в пробирки с ЭДТА, образцы крови предварительно обрабатывали специальным бусрером для лизиса эритроцитов Buffer EL (QIAGEN; Германия), аликвотировали и хранили при $-80{ }^{\circ} \mathrm{C}$. Для выделения геномной PHK использовали набор RNeasy Plus Mini Kit (QIAGEN; Германия) по соответствующему протоколу производителя. Тотальную КДНК из полученных образцов РНК получали с помощью набора для обратной транскрипции и амплисикации кДНК (Евроген; Россия) с добавлением олиго dT праймера, аликвотировали и хранили при $-20{ }^{\circ} \mathrm{C}$. Содержание MPHК гена FXN в исследуемых образцах определяли по пороговому циклу методом ПЦР-РВ с интеркалирующим красителем SYBR Green, с нормированием на референсный ген GAPDH. В качестве метода подсчета уровня экспрессии использовали формулу $2^{(-\Delta \Delta C t)}$.

Статистический анализ осуществляли с помощью программы IBM SPSS Statistics 23 (IBM; CШA) с использованием непараметрических методов статистики: критерия Манна-Уитни, критерия Спирмена. Для ROCанализа применяли программу MedCalc 18 (MedCalc Software; Бельгия).

\section{РЕЗУЛЬТАТЫ ИССЛЕДОВАНИЯ}

\section{Экспрессия гена $F X N$ у носителей гомозиготной и гетерозиготной экспансии}

В группе БФ у пациентов с гомозиготной экспансией GAAповторов уровень экспрессии составил 0,05 [0,00; 0,127]; в группе их родственников с гетерозиготной экспансией - 
0,57 [0,54; 0,66]; в ресреренсной группе контроля - 1,016 $[0,847 ; 1,214]$. Группы статистически значимо различались между собой $(p<0,05)$.

Учитывая перекрывающиеся значения уровней экспрессии между контрольной группой и группой GAA-гетерозигот, был проведен ROC-анализ. Площадь под кривой для анализируемого показателя составила 0,986; при разграничительном значении, равном 0,79, специсичность составила 95\% и чувствительность 93\%. При ROC-анализе результатов оценки экспрессии гена в группах GAA-гетерозигот и GAA-гомозигот площадь под кривой составила 0,934; при разграничительном значении, равном 0,15, специфичность составила 93\% и чувствительность - 87\%.

\section{Клинические сопоставления}

Проводили сопоставления экспрессии FXN с клиническими данными в группе больных БФ. При корреляционном анализе между уровнем экспрессии и возрастом пациентов, возрастом начала и длительностью заболевания, баллом по шкале оценки тяжести атаксии SARA, когнитивными изменениями по МоСА взаимосвязей выявлено не было (p > 0,05). По полученным данным, уровень экспрессии не был связан с наличием кардиомиопатии, нарушением углеводного обмена или костными десормациями ( $p>0,05)$.

В группе сравнения среди родственников с гетерозиготной мутацией наименьший уровень экспрессии FXN был у носительницы гетерозиготной GAA-экспансии (750 GAA-повторов) 72 лет (матери пациента). В анамнезе у обследуемой - многолетняя эндокринопатия (тяжелый сахарный диабет 2-го типа). У других обследованных из группы GAA-гетерозигот сахарного диабета не было.

\section{Генетические сопоставления}

Исследовали корреляцию между уровнем экспрессии MPHK FXN и длиной экспандированных аллелей. В группе БФ экспрессия не была ассоциирована ни с длиной меньшего аллеля GAA1 (статистической значимости не достигала), ни с длиной большего аллеля GAA2. В группе GAA-гетерозигот также не выявлено связи между уровнем экспрессии и длиной экспандированного аллеля GAA2.

\section{Эпигенетические сопоставления}

В работе проведен поиск не-CpG-сайтов во всех исследуемых областях. В промоторной области было обнаружено 2 не-СpG-сайта, в UP-GAA-области не-CpG- сайтов выявлено не было, в DOWN-GAA-области найдено 15 не-СрG-сайтов.

При корреляционном анализе у пациентов с БФ выявлена прямая связь между уровнем экспрессии мРНК гена FXN и уровнем метилирования сайта CpG-54 в UPGAA-области ( $r=0,782 ; p=0,037)$. В области DOWNGAA выявлена обратная корреляция между уровнем экспрессии FXN и уровнем метилирования трех не-CpGсайтов: не-CpG-7a $(r=-0,788 ; p=0,035)$, не-CpG-7b $(r=-0,795 ; p=0,032)$ и не-CpG-8a $(r=-0,875 ; p=0,009)$. Связи уровня метилирования указанных не-СpG-сайтов с длиной GAA1 либо GAA2 выявлено не было. В то же время для рядом расположенных CpG-сайтов метилирование не коррелировало с экспрессией, но зависело от длины экспандированного аллеля (табл. 1).

В группе сравнения у GAA-гетерозигот выявлена корреляция между уровнем экспрессии и уровнем метилирования CpG-13 в промоторной области ( $r=-0,947$; $p=0,017)$, а также между уровнем экспрессии и уровнем метилирования CpG-3 в DOWN-GAA-области ( $r=-0,894$; $p=0,041)$.

С учетом небольшого числа обследуемых в группах нами был проведен расчет корреляций в совмещенной группе, составленной из пациентов, родственников и здоровых добровольцев, с поправкой на группу. Выявленные корреляции между уровнем экспрессии FXN и уровнем метилирования отдельных сайтов представлены в табл. 2. Суммируя полученные результаты, можно отметить, что для CpG-сайтов выявлены обратные корреляции между экспрессией гена и метилированием в промоторе и UPGAA-области и прямые корреляции между экспрессией гена и метилированием в DOWN-GAA-области, тогда как для не-CpG-сайтов в DOWN-GAA-области выявлены обратные корреляции.

Метилированный цитозин в не-CpG-сайтах предшествовал следующим нуклеотидам: сайт 5a - mССС, сайт 7a - mCT, сайт 7b - mCCC, сайт 8a - mCAG, сайт 8b - mCAT, сайт $10 \mathrm{~b}-\mathrm{mCTG}$.

В совмещенной выборке степень метилирования не-CpG-сайтов DOWN-GAA-области не коррелировала с длиной экспансии (GAA1, GAA2) - как и в группе пациентов с БФ.

\section{ОБСУЖДЕНИЕ РЕЗУЛЬТАТОВ}

Недостаточность белка фратаксина при БФ имеет системный эффект и приводит к различным неврологическим и экстраневральным проявлениям заболевания $[1,9]$. Тяжесть генетических изменений при

Таблица 1. Корреляции уровня экспрессии гена FXN и длины экспансии повторов в меньшем аллеле гена с уровнем метилирования не-СрG-сайтов DOWNGAA области и рядом расположенных с ними CpG-сайтов у пациентов с БФ

\begin{tabular}{|c|c|c|c|c|}
\hline $\begin{array}{c}\text { Условные } \\
\text { обозначения сайтов }\end{array}$ & $\begin{array}{c}\text { Корреляция" уровня } \\
\text { метилирования с экспрессией }\end{array}$ & $\begin{array}{c}\text { Корреляция" уровня } \\
\text { метилирования с длиной GAA1 }\end{array}$ & $\begin{array}{c}\text { Последующие за } \\
\text { метилированным цитозином } \\
\text { нуклеотиды }\end{array}$ & $\begin{array}{l}\text { Место расположения } \\
\text { цитозина (GRCh38) }\end{array}$ \\
\hline CpG-7 & - & $-0,901^{*}$ & $\mathrm{mCG}$ & chr9:69,037,380 \\
\hline не-CpG-7а & $-0,788^{*}$ & - & $\mathrm{mCTT}$ & chr9:69,037,382 \\
\hline не-СpG-7b & $-0,795^{*}$ & - & $\mathrm{mCCC}$ & chr9:69,037,388 \\
\hline CpG-8 & - & $-0,836^{*}$ & $\mathrm{mCG}$ & chr9:69,037,390 \\
\hline не-СpG-8а & $-0,875^{\star}$ & - & mCAG & chr9:69,037,397 \\
\hline CpG-9 & - & $-0,772^{*}$ & $\mathrm{mCG}$ & chr9:69,037,420 \\
\hline CpG-10 & - & $-0,791^{*}$ & $\mathrm{mCG}$ & chr9:69,037,434 \\
\hline
\end{tabular}

Примечание: \# - коэффициент корреляции Спирмена $(r) ;{ }^{*}-p<0,05 ;$ «-» — нет корреляционной связи; $\mathrm{mC}$ - метилированный цитозин. 
Таблица 2. Корреляции уровня экспрессии гена FXN и длины экспансии повторов в меньшем аллеле гена с уровнем метилирования не-СрG-сайтов DOWNGAA области и рядом расположенных с ними CpG-сайтов у пациентов с БФ

\begin{tabular}{|c|c|}
\hline Промотор: обратные корреляции & DOWN-GAA: прямые корреляции \\
\hline $\begin{array}{l}\text { - CpG-5 }(r=-0,511)^{\star} \\
\text { - CpG-13 }(r=-0,542)^{\star} \\
\text { - CpG-16 }(r=-0,511)^{\star}\end{array}$ & $\begin{array}{l}\text { - CpG-2 }(r=0,567)^{\star} \\
\text { - CpG-12 }(r=0,520)^{\star}\end{array}$ \\
\hline UP-GAA: обратные корреляции & DOWN-GAA: обратные корреляции \\
\hline $\begin{array}{l}\text { - CpG-43 }(r=-0,615)^{\star} \\
\text { - CpG-44 }(r=-0,508)^{\star} \\
\text { - CpG-45 }(r=-0,533)^{\star}\end{array}$ & $\begin{array}{l}\text { - нe-CpG-5a }(r=-0,514)^{*} \\
\text { - He-CpG-7a }(r=-0,571)^{\star} \\
\text { - нe-CpG-7b }(r=-0,506)^{\star} \\
\text { - He-CpG-8a }(r=-0,625)^{\star} \\
\text { - нe-CpG-8b }(r=-0,644)^{*} \\
\text { - нe-CpG-10b }(r=-0,540)^{\star}\end{array}$ \\
\hline
\end{tabular}

Примечание: * $-p<0,05$.

БФ - длина экспансии GAA-повторов - лишь отчасти может объяснить то многообразие клинической картины, которую наблюдают при данной патологии (вариабельный возраст начала и темп прогрессирования, особенности клинических проявлений, характер полиневропатии и вовлечения кортикоспинальных трактов, тяжесть и характер кардиомиопатии, нарушения углеводного обмена и др.). Закономерно, что поиск объяснения такого широкого фенотипического полиморфизма ведут путем изучения факторов и процессов, регулирующих реализацию генетической информации: метилирования ДНК, модификации гистонов, пространственной организации ДНК, антисмысловых транскриптов и некодирующих РНК. Из-за комплексности и многоплановости процессов, вызванных интронной GAAэкспансией, пока не удается выделить главенствующие мишени, воздействие на которые помогло бы решить проблему недостаточности фратаксина и нарушенной транскрипции FXN, и, следовательно, предложить эффективную терапевтическую стратегию. В работе был сделан акцент на одном из эпигенетических аспектов метилировании ДНК. Данный аспект представляется перспективным в свете появившихся работ по таргетному эпигенетическому редактированию, которое может позволить восстановить нарушенную транскрипцию, как было показано для умственной отсталости на примере экспансии тринуклеотидных повторов в гене FMR1 [12-14].

Результаты по изучению степени экспрессии FXN представлены в ряде зарубежных работ. Так, в одной из них уровень мPHК FXN у пациентов с БФ были снижен до 19\%, у гетерозиготных носителей - до 53\% от уровня контроля, при этом уровень мРНК коррелировал с уровнем фрратаксина, возрастом начала заболевания и длиной экспансии [15]. В другой работе были получены сопоставимые результаты, а также показано, что уровень мРНКи уровень белка фратаксина относительно стабильны во времени и меняются на фоне действия эпигенетической терапии - ингибитора гистоновых деацетилаз. Иными словами, уровень мРНК - измеряемый и изменяемый показатель, который можно использовать в клинических исследованиях [16].

Проведенный нами анализ экспрессии гена FXN выявил также существенное снижение уровня мРНК у пациентов - носителей гомозиготной GAA-экспансии (ниже 15\%) относительно контрольной группы, и в группе родственников с гетерозиготной экспансией повторов (ниже 79\%). Однако в нашем исследовании статистически значимых корреляций ни с клиническими, ни с генетическими характеристиками выявлено не было, вероятнее всего, из-за небольшого размера выборки. При этом обращает на себя внимание тот факт, что в группе гетерозигот у пациентки с сахарным диабетом 2-го типа был выявлен наименьший уровень мPHK FXN. Возможно, у гетерозигот низкий уровень экспрессии МРНК и белка фратаксина может быть предиктором нарушений углеводного обмена, которые наблюдают у пациентов с БФ и могут также быть выявлены у их родственников - гетерозиготных носителей мутации [17, 18].

Работы по исследованию ДНК-метилирования при БФ немногочисленны [8, 19-23]. При этом БФ рассматривают как модельное заболевание с особым типом экспансии тринуклеотидных повторов - на обоих аллелях в некодирующей, регуляторной области гена [20]. В двух работах было обнаружено гиперметилирование нескольких сайтов в UP-GAA-области при БФ [21, 22]. Другие исследователи также показали гиперметилирование UP-GAA и выявили гипометилирование DOWN-GAA в клетках периферической крови пациентов, в головном мозге и миокарде [23], что подтверждает системный эффект экспансии GAA-повторов и информативность данных, получаемых на лейкоцитах периферической крови. Еще в одной работе на большой выборке пациентов с БФ кроме гиперметилирования UP-GAA и гипометилирования DOWN-GAA показана обратная корреляционная связь между уровнем метилирования одного UP-CpG-сайта с уровнем мPHK FXN [8]. Уровень MPHK коррелировал также с количеством GAA-повторов, возрастом начала заболевания, тяжестью симптомов. В нашей ранее опубликованной работе [19] было подтверждено гиперметилирование UP-GAA-области и гипометилирование DOWN-GAA-области при БФ, выявлены прямая связь степени метилирования сайтов UP-GAAобласти с длиной экспансии у гомозиготных носителей мутации и обратная связь степени метилирования сайтов DOWN-GAA-области с длиной экспансии у гетерозиготных носителей мутации.

Данная работа является продолжением предыдущей и исследует влияние эпигенетического профиля FXN на экспрессию соответствующей мРНК. Сопоставляя результаты предыдущей и настоящей работ, можно отметить, что гиперметилирование отдельных CpG-сайтов, располагающихся до области повторов (промотор и UPGAA), связано с меньшим уровнем мРНК и с большим числом тандемных GAA-повторов в гене FXN. B DOWNGAA гипометилирование отдельных CpG-сайтов связано с меньшим уровнем мРНК и с большим числом тандемных GAA-повторов.

Как было отмечено выше, не-CpG-метилирование при БФ до настоящего времени не исследовали. Функциональное значение не-CpG-сайтов обсуждают, 
однако уже сейчас понятно, что оно имеет большое значение в регуляции экспрессии [24]. Не-СpG-сайть преимущественно располагаются там, где меньше плотность CpG-сайтов, т. е. обычно внутри гена. Метилирование не-СpG внутри гена ассоциировано с уменьшением его экспрессии. Считается, что по сравнению с CpG оно более подвержено изменениям, которые могут происходить в процессе развития организма и под воздействием различных факторов окружающей среды [25]. Так, в нейронах на стадии эмбриона не-СрG-сайты практически не метилированы и метилируются в процессе развития. Именно на нейроны приходится наибольшая часть не-CpGметилирования взрослого организма, меньше - на глию, стволовые клетки, гаметы; оно практически отсутствует в других клетках. Ориентировочное соотношение в нейронах не-CpG-метилирования к CpG-метилированию - 1 : 3. Чаще всего первое встречается в динуклеотиде СрА, в меньшей степени - в динуклеотиде СрТ и еще меньше в СpC. Считается, что функция не-CpG-метилирования зависит от молекулярного контекста: так, метилирование цитозина в последовательности mCAC может приводить к снижению экспрессии гена, тогда как метилирование в mCAG - к ее повышению $[10,11]$.

B нашей работе были найдены 2 не-CpG-сайта в промоторной области, в области UP-GAA не-CpG найдены не были, и в DOWN-GAA области выявлены 15 не-CpG. Для сравнения, встречаемость CpG в этих же секвенированных областях следующая: 16 CpG - в промоторе, 67 CpG в UP-GAA и $21 \mathrm{CpG}$ - в DOWN-GAA. Из приведенных данных видно, что чем больше плотность CpG, тем меньше встречаемость не-СpG, и наоборот. Примерное, условное соотношение не-CpG к CpG - 1: 6; напомним, что исследование проводили на лейкоцитах крови, а не на нейронах, с меньшей долей не-CpG.

В работе корреляций уровня метилирования двух неCpG-сайтов в области промотора FXN с уровнем мPHK выявлено не было. В DOWN-GAA-области был выявлен кластер связанных друг с другом, расположенных рядом не-СpG-сайтов, метилирование которых обратно коррелирует с уровнем мРНК, при этом отсутствует связь уровня метилирования с длиной GAA-экспансии. Однонаправленный эффект всех 6 выявленных не-CpGсайтов на экспрессию не зависел от контекста, указанная выше обратная связь отмечена и при конфигурации СрА (mCAC, mCAG), и при СрТ (mCTT, mCTG), и при СpC (2 mCCC).

На совмещенной выборке, в отличие от не-CpGметилирования, уровень CpG-метилирования в DOWNGAA показал прямые ассоциативные связи с уровнем MPHK, что говорит о возможном разнонаправленном эфффекте этих двух типов метилирования. Еще одним различием между ними может быть зависимость от длины GAA-экспансии: при CpG-метилировании она присутствует, тогда как в случае не-СpG не выявляется. Следовательно, не-CpG-метилирование независимо от генетического десекта может модифицировать экспрессию FXN.

Выявленный кластер близкорасположенных не-CpGсайтов, метилирование которых связано с уменьшением транскрипции гена FXN, отстоит от известных и изучаемых при БФ регуляторных последовательностей и мест связывания факторов транскрипции - CTCF, SRF, TFAP2, EGR3, E-box (все они лежат в промоторе и UP-GAAобласти) [26, 27]. Область выявленного не-СрG-кластера, находясь в DOWN-GAA-области, входит в состав Alu (SINE)-элемента. Функциональная значимость последнего до конца не ясна, однако удаление его приводит $k$ существенному нарушению транскрипции FXN $[4,21]$. Это еще раз косвенно подтверждает возможную значимость для транскрипции не-CpG-метилирования данной области.

\section{ВЫВОДЫ}

В работе представлено сопоставление клинических параметров, степени экспансии GAA-повторов и эпигенетических характеристик гена FXN с уровнем мРНК в группах пациентов с БФ, их гетерозиготных родственников и лиц контрольной группы. Выявлены значимые для экспрессии сайты метилирования FXN. В промоторной области и в области UP-GAA для ряда CpG-сайтов определена отрицательная корреляционная связь метилирования с уровнем экспрессии гена, так же как и для ряда не-CpG-сайтов в области DOWN-GAA. Представляется, что выявленный гиперметилированный кластер не-СpG-сайтов можно рассматривать в качестве точки приложения таргетного эпигенетического редактирования с целью увеличения транскрипции FXN и, следовательно, для таргетной терапии БФ.

\section{Литература}

1. Иллариошкин С. Н., Ершова М. В. Атаксия Фридрейха. В книге: Иллариошкин С. Н., Руденская Г. Е., Иванова-Смоленская И. А., Маркова Е. Д., Клюшников С. А. Наследственные атаксии и параплегии. М., 2006; с. 49-113.

2. Burk K. Friedreich ataxia: current status and future prospects. Cerebellum Ataxias. 2017; (4): 4

3. Deutsch EC, Oglesbee D, Greeley NR, Lynch DR. Usefulness of frataxin immunoassays for the diagnosis of Friedreich ataxia. $J$ Neurol Neurosurg Psychiatry. 2014; 85 (9): 994-1002.

4. Yandim C, Natisvivli T, Festenstein R. Gene regulation and epigenetics in Friedreich's ataxia. Journal of neurochemistry. 2013: 126 (Suppl. 1): 21-42

5. Herman D, Jenssen K, Burnett R, Soragni E, Perlman SL, Gottesfeld JM. Histone deacetylase inhibitors reverse gene silencing in Friedreich's ataxia. Nat Chem Biol. 2006; 2 (10): 551-8.

6. Sandi C, Sandi M, Virmouni SA, Al-Mahdawi S, Pook MA Epigenetic-based therapies for Friedreich ataxia. Frontiers in Genetics. 2014; (5): 165
7. Soragni E, Miao W, ludicello M, Jacoby D, De Mercanti S, Clerico M, et al. Epigenetic therapy for Friedreich ataxia. Ann Neurol. 2014; 76 (4): 489-508.

8. Evans-Galea MV, Carrodus N, Rowley SM, Corben LA, Tai G, Saffery $\mathrm{R}$ et al. FXN methylation predicts expression and clinical outcome in Friedreich ataxia. Ann Neurol. 2012; 71 (4): 487-97.

9. Blair IA, Farmer J, Hersch S, Larkindale J, Lynch DR, Napierala J et al. The current state of biomarker research for Friedreich's ataxia: a report from the 2018 FARA biomarker meeting. Future Sci OA. 2019; 5 (6): FSO398

10. He Y, Ecker JR. Non-CG methylation in the human genome. Annu Rev Genomics Hum Genet. 2015; (16): 55-77.

11. Jang HS, Shin WJ, Lee JE, Do JT. CpG and non-CpG methylation in epigenetic gene regulation and brain function. Genes. 2017; (8): e148.

12. Liu XS, Wu H, Krzisch M, Wu X, Graef J, Muffat J, et al. Rescue of Fragile $X$ syndrome neurons by DNA methylation editing of the FMR1 gene. Cell. 2018; (172): 979-92.

13. Lau $\mathrm{C}-\mathrm{H}$, Suh $\mathrm{Y}$. In vivo epigenome editing and transcriptional 
modulation using CRISPR technology. Transgenic Res. 2018; 27 (6): 489-509.

14. Gomez JA, Beitnere U, Segal DJ. Live-animal epigenome editing: Convergence of novel techniques. Trends Genet. 2019; 35 (7): 527-41.

15. Sacca F, Puoro G, Antenora A, Marsili A, Denaro A, Piro R, et al A combined nucleic acid and protein analysis in Friedreich ataxia: Implications for diagnosis, pathogenesis and clinical trial design. PLOS ONE. 2011; 6 (3): e17627.

16. Plasterer HL, Deutsch EC, Belmonte M, Egan E, Lynch DR Rusche JR. Development of frataxin gene expression measures for the evaluation of experimental treatment in Friedreich's ataxia. PLOS ONE. 2013; 8 (5): e63958.

17. Hebinck J, Hardt C, Schols L, Vorgerd M, Briedigkeit L, Kahn CR Ristow M. Heterozygous expansion of the GAA tract of the X25/ frataxin gene is associated with insulin resistance in humans. Diabetes. 2000; 49 (9): 1604-7.

18. McCormick A, Farmer J, Perlman S, Delatycki M, Wilmot G, Matthews $\mathrm{K}$, et al. Impact of diabetes in the Friedreich ataxia clinical outcome measures study. Annals of Clinical and Translational Neurology. 2017; 4 (9): 622-31.

19. Абрамычева Н. Ю., Федотова Е. Ю., Нужный Е. П., Николаева Н. С., Клюшников С. А., Ершова М. В. и др. Эпигенетика болезни Фридрейха: метилирование области экспансии (GAA)n-повторов гена FXN. Вестник Российской академии медицинских наук. 2019; 74 (2): 80-7.

20. Essebier A, Wolf PV, Cao MD, Carroll BJ, Balasubramanian S,

\section{References}

1. Illarioshkin SN., Ershova MV. Ataksiya Fridreykha. V knige: Illarioshkin SN, Rudenskaya GE, Ivanova-Smolenskaya IA. Markova ED, Klyushnikov SA. Nasledstvennye ataksii i paraplegii. M., 2006; s.49-113. Russian.

2. Burk K. Friedreich ataxia: current status and future prospects Cerebellum Ataxias. 2017; (4): 4

3. Deutsch EC, Oglesbee D, Greeley NR, Lynch DR. Usefulness of frataxin immunoassays for the diagnosis of Friedreich ataxia. $J$ Neurol Neurosurg Psychiatry. 2014; 85 (9): 994-1002.

4. Yandim C, Natisvivli T, Festenstein R. Gene regulation and epigenetics in Friedreich's ataxia. Journal of neurochemistry. 2013: 126 (Suppl. 1): 21-42.

5. Herman D, Jenssen K, Burnett R, Soragni E, Perlman SL, Gottesfeld JM. Histone deacetylase inhibitors reverse gene silencing in Friedreich's ataxia. Nat Chem Biol. 2006; 2 (10): $551-8$.

6. Sandi C, Sandi M, Virmouni SA, Al-Mahdawi S, Pook MA. Epigenetic-based therapies for Friedreich ataxia. Frontiers in Genetics. 2014; (5): 165

7. Soragni E, Miao W, ludicello M, Jacoby D, De Mercanti S, Clerico M, et al. Epigenetic therapy for Friedreich ataxia. Ann Neurol. 2014; 76 (4): 489-508.

8. Evans-Galea MV, Carrodus N, Rowley SM, Corben LA, Tai G, Saffery $R$, et al. FXN methylation predicts expression and clinical outcome in Friedreich ataxia. Ann Neurol. 2012; 71 (4): 487-97.

9. Blair IA, Farmer J, Hersch S, Larkindale J, Lynch DR, Napierala J, et al. The current state of biomarker research for Friedreich's ataxia: a report from the 2018 FARA biomarker meeting. Future Sci OA. 2019; 5 (6): FSO398.

10. He Y, Ecker JR. Non-CG methylation in the human genome. Annu Rev Genomics Hum Genet. 2015; (16): 55-77.

11. Jang HS, Shin WJ, Lee JE, Do JT. CpG and non-CpG methylation in epigenetic gene regulation and brain function. Genes. 2017; (8): $\mathrm{e} 148$.

12. Liu XS, Wu H, Krzisch M, WuX, Graef J, Muffat J, et al. Rescue of Fragile $X$ syndrome neurons by DNA methylation editing of the FMR1 gene. Cell. 2018; (172): 979-92.

13. Lau C-H, Suh Y. In vivo epigenome editing and transcriptional modulation using CRISPR technology. Transgenic Res. 2018; 27 (6): 489-509.

14. Gomez JA, Beitnere U, Segal DJ. Live-animal epigenome editing:
Boden M. Statistical enrichment of epigenetic states around triplet repeats that can undergo expansions. Front Neurosci. 2016; (10): 92.

21. Greene E, Mahishi L, Entezam L, Kumari D, Usdin K. Repeatinduced epigenetic changes in intron 1 of the frataxin gene and its consequences in Friedreich ataxia. Nucleic Acids Research. 2007; 35 (10): 3383-90.

22. Castaldo I, Pinelli M, Monticelli A, Acquaviva F, Giacchetti $M$ Filla $A$, et al. DNA methylation in intron 1 of the frataxin gene is related to GAA repeat length and age of onset in Friedreich ataxia patients. J Med Genet. 2008; 45 (12): 808-12.

23. Al-Mahdawi S, Pinto RM, Ismail O, Varshney D, Lymperi S, Sandi C et al. The Friedreich ataxia GAA repeat expansion mutation induces comparable epigenetic changes in human and transgenic mouse brain and heart tissues. Hum Mol Genet. 2008; (17): 735-46.

24. Patil V, Ward RL, Hesson LB. The evidence for functional non-CpG methylation in mammalian cells. Epigenetics. 2014; 9 (6): 823-28.

25. Fuso A, Lucarelli M. CpG and non-CpG methylation in the dietepigenetics-neurodegeneration connection. Curr Nutr Rep. 2019; 8 (2): 74-82.

26. Li K, Singh A, Crooks DR, Dai X, Cong Z, Pan L, et al. Expression of human frataxin is regulated by transcription factors SRF and TFAP2. PLOS ONE. 2010; 5 (8): e12286.

27. Al-Mahdawi S, Sandi C, Pinto RM, Pook MA. Friedreich ataxia patient tissues exhibit increased 5-hydroxymethylcytosine modification and decreased CTCF binding at the FXN locus. PLOS ONE. 2013; 8 (9): e74956.

Convergence of novel techniques. Trends Genet. 2019; 35 (7): 527-41.

15. Sacca F, Puoro G, Antenora A, Marsili A, Denaro A, Piro R, et al. A combined nucleic acid and protein analysis in Friedreich ataxia: Implications for diagnosis, pathogenesis and clinical trial design. PLoS ONE. 2011; 6 (3): e17627.

16. Plasterer HL, Deutsch EC, Belmonte M, Egan E, Lynch DR, Rusche JR. Development of frataxin gene expression measures for the evaluation of experimental treatment in Friedreich's ataxia. PLOS ONE. 2013; 8 (5): e63958.

17. Hebinck J, Hardt C, Schols L, Vorgerd M, Briedigkeit L, Kahn CR, Ristow M. Heterozygous expansion of the GAA tract of the X25/ frataxin gene is associated with insulin resistance in humans. Diabetes. 2000; 49 (9): 1604-7.

18. McCormick A, Farmer J, Perlman S, Delatycki M, Wilmot G, Matthews K, et al. Impact of diabetes in the Friedreich ataxia clinical outcome measures study. Annals of Clinical and Translational Neurology. 2017; 4 (9): 622-31.

19. Abramycheva NYu, Fedotova EYu, Nuzhniy EP, Nikolaeva NS, Klyushnikov SA, Ershova MV, i dr. Epigenetika bolezni Fridreykha: metilirovanie oblasti ekspansii (GAA)n-povtorov gena FXN. Vestnik Rossiyskoy akademii meditsinskikh nauk. 2019; 74 (2): 80-7.

20. Essebier A, Wolf PV, Cao MD, Carroll BJ, Balasubramanian S, Boden M. Statistical enrichment of epigenetic states around triplet repeats that can undergo expansions. Front Neurosci. 2016; (10): 92.

21. Greene E, Mahishi L, Entezam L, Kumari D, Usdin K. Repeatinduced epigenetic changes in intron 1 of the frataxin gene and its consequences in Friedreich ataxia. Nucleic Acids Research. 2007; 35 (10): 3383-90.

22. Castaldo I, Pinelli M, Monticelli A, Acquaviva F, Giacchetti M, Filla $A$, et al. DNA methylation in intron 1 of the frataxin gene is related to GAA repeat length and age of onset in Friedreich ataxia patients. J Med Genet. 2008; 45 (12): 808-12.

23. Al-Mahdawi S, Pinto RM, Ismail O, Varshney D, Lymperi S, Sandi $C$, et al. The Friedreich ataxia GAA repeat expansion mutation induces comparable epigenetic changes in human and transgenic mouse brain and heart tissues. Hum Mol Genet. 2008; (17): $735-46$

24. Patil $V$, Ward RL, Hesson LB. The evidence for functional non-CpG methylation in mammalian cells. Epigenetics. 2014; 9 (6): 823-28. 
25. Fuso A, Lucarelli M. CpG and non-CpG methylation in the dietepigenetics-neurodegeneration connection. Curr Nutr Rep. 2019; 8 (2): 74-82.

26. Li K, Singh A, Crooks DR, Dai X, Cong Z, Pan L, et al. Expression of human frataxin is regulated by transcription factors SRF and
TFAP2. PLoS ONE. 2010; 5 (8): e12286.

27. Al-Mahdawi S, Sandi C, Pinto RM, Pook MA. Friedreich ataxia patient tissues exhibit increased 5-hydroxymethylcytosine modification and decreased CTCF binding at the FXN locus. PLoS ONE. 2013; 8 (9): e74956. 